\title{
Perancangan Struktur Tata Kelola Data di Pemerintah Daerah Menggunakan Framework Data Management Body Of Knowledge
}

Designing Local Government Data Governance Structure Using the Data Management Body Framework of Knowledge

\author{
Nugroho Setio Wibowo ${ }^{1)}$, Ema Utami ${ }^{2}$, Hanif Al Fatta ${ }^{3)}$ \\ 1),2),3) Magister Teknik Informatika, Universitas AMIKOM Yogyakarta \\ Jl. Ring Road Utar, Condong Catur, Depok, Sleman, Yogyakarta 55281 \\ Email : nugroho.wibowo@students.amikom.ac.id ${ }^{1)}, \underline{\text { ema.u@amikom.ac.id }}^{2)}$ hanif.a@amikom.ac.id $^{3)}$
}

\begin{abstract}
Abstrak - Sesuai Peraturan Presiden no 39 tahun 2019 tentang Satu Data, untuk memperoleh Data yang akurat, mutakhir, terpadu, mudah diakses, dan dibagipakaikan, diperlukan perbaikan tata kelola Data yang dihasilkan oleh pemerintah. Studi kasus penelitian ini di Pemerintah Kabupaten Trenggalek Jawa Timur di 35 Organisasi Perangkat Daerah (OPD) dengan metode kuisioner dan wawancara untuk penggalian permasalahan data. Perumusan pengolahan data menggunakan pedoman Data Management Body Of Knowledge (DMBOK. Data Management Body Of Knowledge (DMBOK) merupakan salah satu framework tata kelola data yang memberikan pendekatan model tata kelola data secara fungsional, lengkap dan menyeluruh dalam membangun tata kelola data di organisasi. Penelitian ini merumuskan struktur tatakelola data, peran tata kelola data dalam struktur organisasi pemerintahan Kabupaten Trenggalek, peran aktivitas tata kelola data dan pemetaan solusi 18 masalah data di Pemerintah Kabupaten Trenggalek berdasarkan pedoman DMBOK. Hasil dari penelitian ini menunjukkan bahwa tata kelola data dengan pedoman DMBOK dapat digunakan sebagai solusi untuk masalah data yang terjadi. Struktur tata kelola data yang telah dirancang diharapkan dapat membantu Kabupaten Trenggalek dalam mengimplementasikan tata kelola data di pemerintah daerah secara efektif
\end{abstract}

Kata kunci-DMBOK; Kabupaten Trenggalek; Satu Data; Tata Kelola Data

Abstract - In accordance with Presidential Regulation No.39 of 2019 concerning One Data, to obtain accurate, up-to-date, integrated, easily accessible and shared data, it is necessary to improve the governance of data produced by the government. This research case study in the Trenggalek Regency Government of East Java in 35 Regional Apparatus Organizations $(O P D)$ using questionnaires and interviews to explore data problems. The formulation of data processing uses the Data Management Body Of Knowledge (DMBOK) guidelines. Data Management Body Of Knowledge (DMBOK) is a data governance framework that provides a functional, complete and comprehensive approach to data governance models in building data governance in organizations. This formulates the structure of data management, the role of data management in the organizational structure of Trenggalek Regency government, the role of data management activities and mapping solutions to 18 data problems in the Trenggalek Regency Government based on DMBOK guidelines. The results of this study indicate that data management with DMBOK guidelines can be used as a solution to data problems that occur. The data governance structure that has been designed is expected to help Trenggalek Regency in implementing data governance in the local government effectively.

Keywords -DMBOK; Trenggalek Regency One Data,; Data Governance

\section{PENDAhULUAN}

Interoperabilitas data merupakan faktor yang penting dalam integrasi sistem informasi. Interoperabilitas didefinisikan sebagai kemampuan organisasi pemerintah untuk saling berbagi dan mengintegrasikan informasi dan proses kerjanya,dengan memanfaatkan sekumpulan standar yang baku.[1]

Sesuai Peraturan Presiden no 39 tahun 2019 tentang Satu Data, untuk memperoleh data yang akurat, mutakhir, terpadu, dapat dipertanggungjawabkan, mudah diakses, dan dibagipakaikan, diperlukan perbaikan tata kelola Data yang dihasilkan oleh pemerintah. Data Management Body Of Knowledge (DMBOK) merupakan salah satu framework tata kelola data yang memberikan pendekatan model tata kelola data secara fungsional, lengkap dan menyeluruh dalam membangun 
tata kelola data di organisasi.[2]

DAMA International mengungkapkan bahwa saat ini organisasi telah menempatkan data dan informasi sebagai organisasi aset yang membantu dalam mencapai tujuan organisasi, sehingga itu perlu dikelola secara efektif. Kerjasama antara sisi bisnis dan teknologi informasi (TI) perlu dilakukan untuk menyediakan dan mengendalikan data dan informasi. Manajemen data adalah fungsi bisnis dalam mengelola dan menyediakan aset data dan informasi.[3]

Di Kabupaten Trenggalek ketersediaan data pada sistem perencanaan kini menjadi hal yang sangat mendesak. Terdapat 19 OPD yang belum online, datanya juga masih dikelola secara manual dan masih tersebar sehingga belum dapat dimanfaatkan oleh dinas lain. [4]

Ketersediaan data untuk interoperabilitas dalam perencanaan ini disebut data primer/data induk. Data primer atau data induk ini merupakan prasyarat utama integrasi sistem di pemerintah daerah. [5]

Penelitian Ni Luh Aniek Laksmidewi menyampaikan bahwa tumpang tindihnya penyediaan data yang berujung pada ketidakakuratan informasi. Interoperabilitas merupakan salah satu solusi dan dalam implementasinya diperlukan sebuah framework.[6]

Struktur Tata Kelola Data dalam implementasinya harus diatur oleh organisasi yang bertindak sebagai badan pengatur. Desain struktur tata kelola data sangat penting untuk implementasi program tata kelola data itu sendiri.

Panduan DMBOK dilakukan oleh penelitipeneliti sebelumnya dalam perancangan tata kelola data. Penelitian [7] yang dilakukan Ferra Arik Tridalestari dkk tatakelola data memegang peranan yang penting dalam suksesnya implementasi interoperabilitas data. Tata kelola Data yang efektif dapat meningkatkan kualitas, ketersediaan dan integritas data dengan meningkatkan kolaborasi lintas-organisasi yang terstruktur terhadap kebijakan. Penelitian yang dilakukan adalah melakukan identifikasi kebutuhan tata kelola data diperguruan tinggi dengan referensi DAMA International melalui pemetaan dan pengukuran terhadap proses bisnis yang didasarkan pada konsep Tridharma perguruan tinggi.

Penelitian lainnya [3] mengembangkan tata kelola dan manajemen data struktur berdasarkan pedoman Badan Manajemen Data
PT Pengetahuan (DMBOK). Hasil penelitian ini adalah standar dan pedoman untuk mendukung implementasi tata kelola data dalam LPS secara efektif.

Penelitian lainnya [8] merancang tata kelola teknologi informasi di PT Kereta Api Indonesia agar dapat diimplementasikan untuk meningkatkan kinerja perusahaan. Perancangan ini menggunakan DMBOK untuk melakukan perancangan tata kelola data terkait Reference and Master data pada PT.Kereta Api Indonesia.

Penelitian lainnya [9] menggunana DMBOK untuk memberikan solusi terkait Reference dan Master Data eference dan Master Data di Pemerintah Kabupaten Bandung.

Penelitian selanjutnya [10] menggunakan studi dokumen dan beberapa sesi wawancara bertujuan untuk mengukur seberapa baik data Manajemen Kualitas (DQM) di BMKG menggunakan DMBOK. Hasil Penelitian menunjukan tingkat kematangan data managemen di BMKG dan rekomendasinya.

Mempertimbangkan studi yang dilakukan [3] menggunakan kerangka DMBOK ini diadopsi dalam penelitian ini sebagai bagian dari pedoman yang difokuskan untuk tatakelola data yang ada di Kabupaten Trenggalek.

Pedoman DMBOK dalam gambar 1 menghasilkan struktur Tata Kelola Data di Pemerintah Kabupaten Trenggalek termasuk peran, bidang keputusan, dan tanggung jawab.

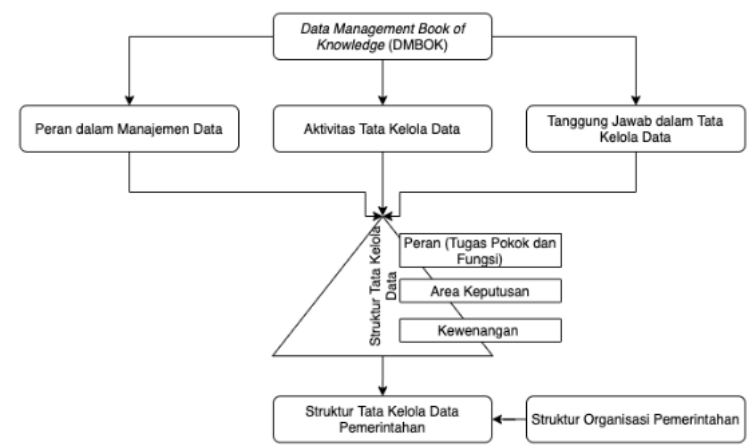

Gambar 1 Kerangka Struktur Tata Kelola Data

\section{LANDASAN TEORI}

Kebijakan Pemerintah Indonesia untuk mendukung proses pengambilan keputusan berbasis data diatur dalam Perpres No. 39 Tahun 2019 tentang Satu Data Indonesia.[11] Untuk mewujudkan hal tersebut, maka diperlukan pemenuhan atas data pemerintah yang akurat, terbuka, dan interoperabel atau mudah dibagi pakaikan antar pengguna data 
Pemerintah Kabupaten Trenggalek harus menangani 95 kelompok urusan dan 216 layanan publik seperti yang tertuang indikator kinerja yang ada di Rencana Panjang Rencana Pembangunan Jangka Menengah Daerah (RPJMD) tahun 2016-2021 [4]

Dengan cukup banyaknya kelompok urusan dan layanan publik yang harus ditangani, perlu pengelolaan data yang baik sesuai prinsip yang diatur dalam Perpres tersebut antara lain memenuhi standar data, memiliki metadata, memenuhi kaidah Interoperabilitas (penyebaran) Data, dan menggunakan kode referensi dan/atau data induk.

Pemahaman mengenai uraian tugas yang baik akan sangat mempengaruhi kinerja perangkat daerah dan ketersediaan datanya, sehingga perlua tata kelola tugas dan fungsi organisasi perangkat daerah yang baik.[12]

DAMA International mengungkapkan bahwa saat ini organisasi telah menempatkan data dan informasi sebagai organisasi aset yang membantu dalam mencapai tujuan organisasi, sehingga itu perlu dikelola secara efektif. [13]

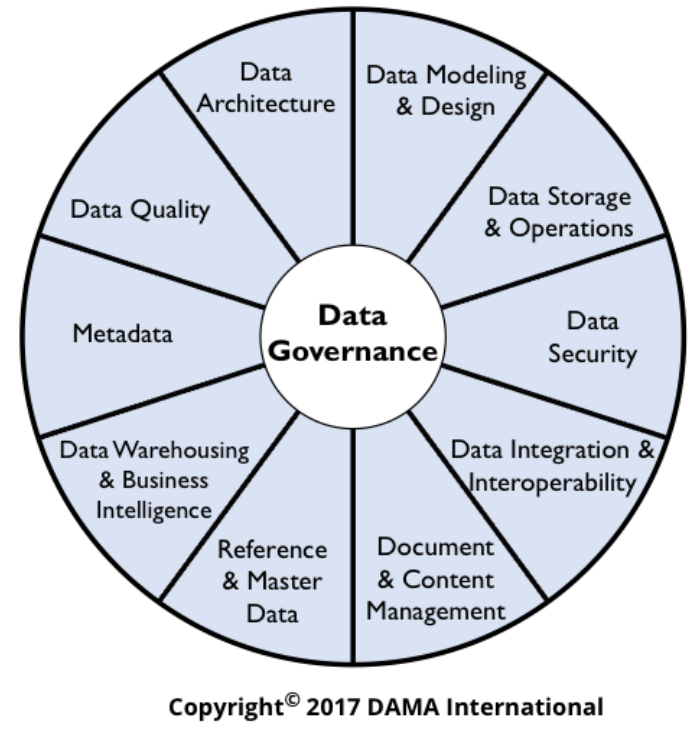

Gambar 2 Wheel DMBOK

Dalam gambar 2, Framework DAMA international memperlihatkan bahwa fungsi tata kelola data merupakan inti. Fungsi tata kelola data berinteraksi dan mempengaruhi fungsi lain yang mengelilinginya. Tata kelola data berkaitan dengan otoritas dan kendali (perencanaan, pengawasan, pelaksanaan) terhadap aset data

Aktivitas dalam Tata Kelola Data mengelola atau menghasilkan strategi data, kebijakan data, arsitektur data, data standar dan prosedur data, kepatuhan terhadap peraturan, masalah manajemen, proyek manajemen data, manajemen data layanan, penilaian aset data, komunikasi dan promosi.

Struktur Tata Kelola Data Tata kelola data dalam implementasinya harus diatur oleh organisasi yang bertindak sebagai badan pengatur. Desain struktur tata kelola data sangat penting untuk implementasi program tata kelola data itu sendiri. Penelitian pemetaan permasalahan tatakelola data ini menggunakan matrik pemetaan seperti digambar 3 [2]

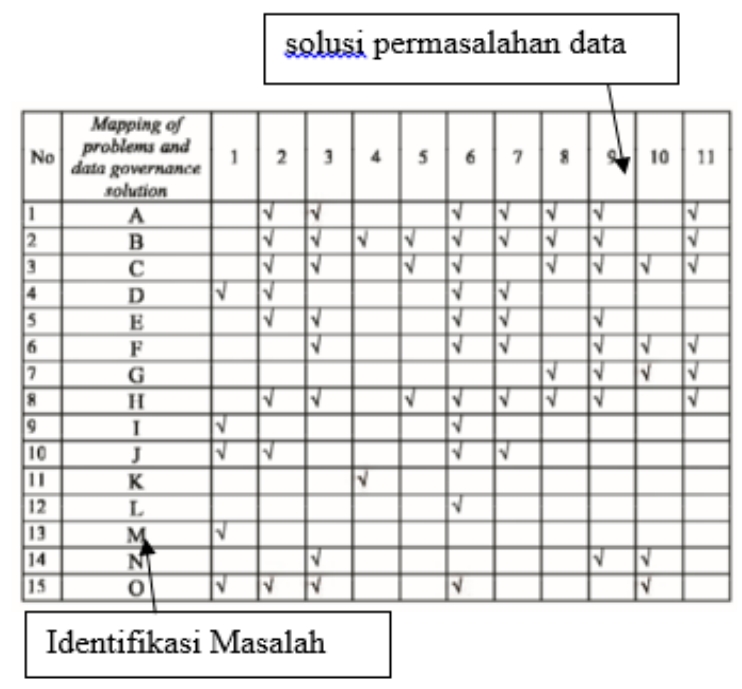

gambar 3 Matrik permasalaan tatakelola data

\section{METODE}

Penelitian ini menggunakan metode kualitatif dengan pendekatan survey. Pengertian survey dibatasi pada penelitian yang datanya dikumpulkan dari sampel atas populasi untuk mewakili seluruh populasi. Dengan demikian penelitian survey adalah penelitian yang mengambil sampel dari satu populasi dan menggunakan kuesioner sebagai alat pengumpulan data yang pokok.[14] Tahapan penelitian ini dimulai dengan. pengumpulan data yang dilakukan dengan menyebar form survey dan wawancara yang ada di Organisasi Perangkat Daerah Pemerintah Kabupaten Trenggalek sebanyak 35 Organisasi Perangkat Daerah (OPD) dengan melibatkan penanggungjawab sistem di OPD masingmasing untuk mengindentifikasi terkait permasalahan tata kelola data. [15]

Tahap selanjutnya adalah memproses data yang sudah dikumpulkan dengan panduan kerangka kerja yang di DMBOK. Analisa tatakelola data kemudian solusi pemecahan masalah terkait hal tersebut mengacu dengan 
panduaan/framework di DMBOK [1].

Tahap selanjutnya adalah merancang struktur tata kelola data sesuai dengan struktur organisasi yang ada di Pemerintah Kabupaten Trenggalek. Dalam merancang struktur tata kelola data, ditentukan juga peran, bidang keputusan, dan tanggung jawab yang dilakukan.

Desain peran dilakukan dengan menggunakan wawancara dan mengadaptasi peraturan tentang organisasi Kedudukan, Susunan Organisasi, Tugas Dan Fungsi Serta Tata Kerja Dinas Daerah di Pemerintah Kabupaten Trenggalek.[16]

Hasil dari pengolahan data ini adalah rancangan struktur/pembagian wewenang pengelola data dan matrik solusi atas permasalahan data.

Laporan penelitian dikonfirmasi dalam forum group discussion dengan Dinas Komunikasi dan Informatika Kabupaten Trenggalek sehingga hasilnya bisa dipertanggungjawabkan.

Selanjutnya kesimpulan dibuat sebagai tahapan terakhir dari penelitian ini.

\section{HASIL DAN PEMBAHASAN}

\section{A. Identifikasi Permasalahan Data}

Sebelum diterapkannya manajemen data menggunakan kerangka kerja DMBOK, telah dilakukan survey terlebih dahulu dengan menganalisis data-data pemerintahan, dan identifikasi masalah-masalah data yang terjadi di Kabupaten Trenggalek. Identifikasi permasalahan data dapat ditentukan dengan cara mewawancarai dan survey ke pihak-pihak berkepentingan seperti kepala bidang atau perwakilan di 35 Organisasi Perangkat Daerah (OPD). Berdasarkan identifikasi masalahmasalah tersebut, tabel 1 menunjukkan ringkasan masalah data pada OPD.

Tabel 1 Identifikasi Masalah

\begin{tabular}{cl}
\hline Kode & \multicolumn{1}{c}{ Identifikasi Masalah } \\
\hline A & $\begin{array}{l}\text { Aktivitas manajemen data masih dilakukan } \\
\text { di masing-masing OPD }\end{array}$ \\
\hline B & $\begin{array}{l}\text { Sumber data / Database masih terpencar- } \\
\text { pencar untuk setiap OPD }\end{array}$ \\
\hline C & $\begin{array}{l}\text { Budaya organisasi belum terbiasa dengan } \\
\text { manajemen data terpusat }\end{array}$ \\
\hline
\end{tabular}

\begin{tabular}{|c|c|}
\hline Kode & Identifikasi Masalah \\
\hline $\mathrm{D}$ & $\begin{array}{l}\text { Belum ada prosedur formal validasi kualitas } \\
\text { data }\end{array}$ \\
\hline $\mathrm{E}$ & $\begin{array}{l}\text { Beberapa data masih bersumber dari excel, } \\
\text { word, pdf }\end{array}$ \\
\hline $\mathrm{F}$ & $\begin{array}{l}\text { Tidak ada pembagian kewenangan untuk } \\
\text { masing-masing OPD mengenai manajemen } \\
\text { data }\end{array}$ \\
\hline G & $\begin{array}{l}\text { Memiliki banyak aplikasi yang masih tidak } \\
\text { terintegrasi (silo) }\end{array}$ \\
\hline $\mathrm{H}$ & $\begin{array}{l}\text { Tingkat keandalan Diskominfo sebagai pusat } \\
\text { data informasi belum baik }\end{array}$ \\
\hline I & $\begin{array}{l}\text { Keterbatasan kemampuan interoperabilitas } \\
\text { data internal dan eksternal yang disebabkan } \\
\text { oleh perbedaan struktur data }\end{array}$ \\
\hline $\mathrm{J}$ & $\begin{array}{l}\text { Secara umum perhatian terhadap keamanan } \\
\text { informasi dan kerahasiaan data masih kurang }\end{array}$ \\
\hline $\mathrm{K}$ & $\begin{array}{l}\text { Tidak adanya regulasi/standar terkait dengan } \\
\text { integrasi dan tata kelola data }\end{array}$ \\
\hline $\mathrm{L}$ & $\begin{array}{l}\text { Belum ada kesadaran untuk melakukan } \\
\text { update data ketika terjadi perubahan pada } \\
\text { objek }\end{array}$ \\
\hline M & $\begin{array}{l}\text { Masih ada beberapa aplikasi yang belum } \\
\text { memanfaatkan sumber data yang dikelola } \\
\text { oleh Diskominfo (belum terintegrasi) }\end{array}$ \\
\hline $\mathrm{N}$ & $\begin{array}{l}\text { Belum terdapat Sistem Portal Data (Data } \\
\text { Warehouse) }\end{array}$ \\
\hline $\mathrm{O}$ & $\begin{array}{l}\text { Terjadi Pencurian Data \& Informasi } \\
\text { (Hacking) }\end{array}$ \\
\hline $\mathrm{P}$ & $\begin{array}{l}\text { Aplikasi yang dikembangkan oleh pihak } \\
\text { ketiga tidak memberikan source code } \\
\text { sehingga sulit untuk melakukan integrasi }\end{array}$ \\
\hline Q & $\begin{array}{l}\text { Aplikasi yang dikembangkan oleh } \\
\text { Kementerian tidak open source }\end{array}$ \\
\hline $\mathrm{R}$ & Adanya data yang hilang atau rusak \\
\hline
\end{tabular}

Kemudian dibuatkan solusi atas ringkasan tiap permasalahan tersebut yang dibuat pada tabel 2 yang mengacu dengan pedoman yang ada di DMBOK.

Tabel 2 Solusi Pengelolaan Data

\begin{tabular}{ccl}
\hline Kode & \multicolumn{1}{c}{ Isu } & Solusi Pengelolaan Data \\
\hline 1 & Kualitas data & $\begin{array}{l}\text { Perlu ada mekanisme } \\
\text { validasi kualitas data }\end{array}$ \\
\hline 2 & Standar data & $\begin{array}{l}\text { Menyusun standar data } \\
\text { (meta-data) }\end{array}$ \\
\hline 3 & Regulasi data & $\begin{array}{l}\text { Menyusun regulasi terkait } \\
\text { kewenangan data (Wali } \\
\text { Data) }\end{array}$ \\
\hline
\end{tabular}




\begin{tabular}{|c|c|c|}
\hline Kode & Isu & Solusi Pengelolaan Data \\
\hline 4 & $\begin{array}{l}\text { Klasifikasi } \\
\text { data }\end{array}$ & $\begin{array}{l}\text { Penentuan klasifikasi data } \\
\text { (Publik, Rahasia) }\end{array}$ \\
\hline 5 & $\begin{array}{l}\text { Koordinasi } \\
\text { data }\end{array}$ & $\begin{array}{l}\text { Membentuk Forum Data } \\
\text { sebagai platform } \\
\text { komunikasi lintas OPD }\end{array}$ \\
\hline 6 & $\begin{array}{l}\text { Arsitektur } \\
\text { Data }\end{array}$ & $\begin{array}{l}\text { Menyusun arsitektur data } \\
\text { dan aplikasi }\end{array}$ \\
\hline 7 & Integrasi data & $\begin{array}{l}\text { Membentuk Tim Integrasi } \\
\text { Data dan Aplikasi }\end{array}$ \\
\hline 8 & $\begin{array}{l}\text { Pengelola } \\
\text { data }\end{array}$ & $\begin{array}{l}\text { Membentuk Tim Pengelola } \\
\text { Data }\end{array}$ \\
\hline 9 & $\begin{array}{l}\text { Pengelola } \\
\text { keamanan } \\
\text { data }\end{array}$ & $\begin{array}{l}\text { Membentuk Tim Keamanan } \\
\text { Informasi }\end{array}$ \\
\hline 10 & $\begin{array}{l}\text { Keamanan } \\
\text { data }\end{array}$ & $\begin{array}{l}\text { Melakukan penetration } \\
\text { testing }\end{array}$ \\
\hline 11 & $\begin{array}{l}\text { Data berbagi } \\
\text { pakai }\end{array}$ & $\begin{array}{l}\text { Negosiasi dan review } \\
\text { perjanjian berbagi data } \\
(\mathrm{MoU})\end{array}$ \\
\hline 12 & Infrastruktur & $\begin{array}{l}\text { Mengembangkan } \\
\text { infrastruktur dan sistem } \\
\text { informasi untuk mengolah } \\
\text { data }\end{array}$ \\
\hline 13 & Bisnis proses & $\begin{array}{l}\text { Melakukan analisis bisnis } \\
\text { proses }\end{array}$ \\
\hline 14 & $\begin{array}{l}\text { Standar } \\
\text { teknologi }\end{array}$ & $\begin{array}{l}\text { Menyusun standar } \\
\text { pengembangan infrastruktur } \\
\text { dan sistem informasi }\end{array}$ \\
\hline 15 & $\begin{array}{l}\text { Pemrosesan } \\
\text { data }\end{array}$ & $\begin{array}{l}\text { Melakukan scrapping data \& } \\
\text { Extract Transform Load }\end{array}$ \\
\hline 16 & Integrasi & $\begin{array}{l}\text { Mengintegrasikan sistem } \\
\text { informasi dengan } \\
\text { mengembangkan API }\end{array}$ \\
\hline 17 & Publikasi data & $\begin{array}{l}\text { Mengembangkan sistem } \\
\text { portal data }\end{array}$ \\
\hline 18 & Backup data & $\begin{array}{l}\text { Melakukan backup data } \\
\text { secara berkala dan } \\
\text { melakukan restore data } \\
\text { ketika terjadi kehilangan dan } \\
\text { kerusakan data }\end{array}$ \\
\hline
\end{tabular}

\section{B. Menentukan Solusi Atas Permasalahan}

Rancangan struktur tata kelola data yang diatur dalam kerangka DMBOK yang ditunjukkan gambar 4 menjadi dasar untuk menentukan solusi masalah data. Tahapan pertama ialah dengan memetakan peran dalam tata kelola data dengan struktur organisasi yang ada dalam pemerintah Kabupaten Trenggalek.

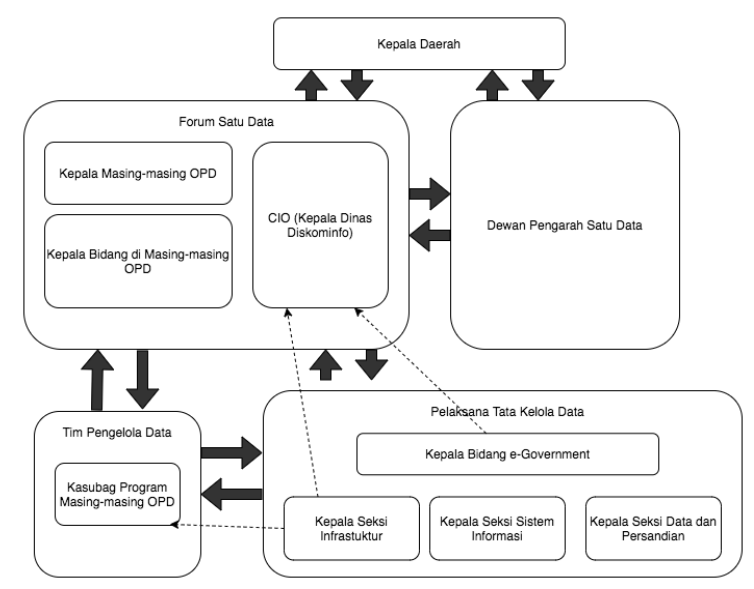

Gambar 4 Rancangan Struktur Organisasi

Pemetaan elemen masing-masing tata kelola data dalam struktur organisasi pemerintah Kabupaten Trenggalek ditunjukkan di tabel 3 .

Tabel 3 Elemen Struktur Pemerintah

\begin{tabular}{|c|c|c|}
\hline No & Peran & $\begin{array}{c}\text { Elemen-elemen dalam } \\
\text { Struktur Organisasi } \\
\text { Pemerintah }\end{array}$ \\
\hline 1 & $\begin{array}{l}\text { Manajemen } \\
\text { Eksekutif }\end{array}$ & Kepala Daerah \\
\hline 2 & $\begin{array}{l}\text { Dewan Pengarah } \\
\text { Satu Data }\end{array}$ & $\begin{array}{l}\text { Sekda, Bappeda, Diskominfo, } \\
\text { Kepala Badan Pusat Statistik }\end{array}$ \\
\hline 3 & Forum Satu Data & $\begin{array}{l}\text { Kepala Diskominfo, Kepala } \\
\text { Masing-masing OPD, Kepala } \\
\text { Bidang di Masing-masing } \\
\text { OPD }\end{array}$ \\
\hline 4 & $\begin{array}{l}\text { Tim Pengelola } \\
\text { Data }\end{array}$ & $\begin{array}{l}\text { Kasubag Program Masing- } \\
\text { masing OPD }\end{array}$ \\
\hline 5 & $\begin{array}{l}\text { Pelaksana Tata } \\
\text { Kelola Data }\end{array}$ & $\begin{array}{l}\text { Kepala Bidang e-Government, } \\
\text { Kepala Seksi Infrastruktur, } \\
\text { Kepala Seksi Sistem } \\
\text { Informasi, Kepala Seksi Data } \\
\text { dan Persandian }\end{array}$ \\
\hline 6 & Arsitek Data & Kepala Seksi Tata Kelola \\
\hline 7 & $\begin{array}{l}\text { Analis Gudang } \\
\text { Data }\end{array}$ & $\begin{array}{l}\text { Kepala Seksi Sistem } \\
\text { Informasi }\end{array}$ \\
\hline 8 & $\begin{array}{l}\text { Spesialis Meta- } \\
\text { data }\end{array}$ & $\begin{array}{l}\text { Kepala Seksi Data dan } \\
\text { Persandian }\end{array}$ \\
\hline 9 & $\begin{array}{l}\text { Analis Kualitas } \\
\text { Data }\end{array}$ & $\begin{array}{l}\text { Kepala Bidang di Masing- } \\
\text { masing OPD }\end{array}$ \\
\hline 10 & $\begin{array}{l}\text { Administrator } \\
\text { Data }\end{array}$ & Kasubag Program \\
\hline 11 & Administrator & Kasubag Program \\
\hline
\end{tabular}




\begin{tabular}{|c|c|c|}
\hline No & Peran & $\begin{array}{c}\text { Elemen-elemen dalam } \\
\text { Struktur Organisasi } \\
\text { Pemerintah }\end{array}$ \\
\hline 12 & $\begin{array}{l}\text { Arsitek Integrasi } \\
\text { Data }\end{array}$ & Kepala Bidang e-Government \\
\hline 13 & $\begin{array}{l}\text { Spesialis } \\
\text { Integrasi Data }\end{array}$ & Kepala Bidang e-Government \\
\hline 14 & $\begin{array}{l}\text { Analis } \\
\text { Kecerdasan } \\
\text { Bisnis/Administr } \\
\text { ator }\end{array}$ & $\begin{array}{l}\text { Kepala Bidang di Masing- } \\
\text { masing OPD }\end{array}$ \\
\hline 15 & $\begin{array}{l}\text { Arsitek } \\
\text { Enterprise Data }\end{array}$ & Kepala Bidang e-Government \\
\hline 16 & $\begin{array}{l}\text { Administrator } \\
\text { Help Desk }\end{array}$ & $\begin{array}{l}\text { Kepala Seksi Data dan } \\
\text { Persandian }\end{array}$ \\
\hline 17 & $\begin{array}{l}\text { Fasilitator Forum } \\
\text { Satu Data }\end{array}$ & $\begin{array}{l}\text { Kepala Seksi Data dan } \\
\text { Persandian }\end{array}$ \\
\hline
\end{tabular}

Di dalam struktur tata kelola data, terdapat daftar aktivitas-aktivitas tata kelola data di tabel $\underline{4}$ sebagai berikut:

Tabel 4 Aktivitas Tata Kelola Data

\begin{tabular}{|c|c|c|}
\hline No & Kode & Aktivitas Tata Kelola Data \\
\hline 1 & ACT-1 & $\begin{array}{l}\text { Perlu ada mekanisme validasi kualitas } \\
\text { data }\end{array}$ \\
\hline 2 & ACT-2 & Menyusun standar data (metadata) \\
\hline 3 & ACT-3 & $\begin{array}{l}\text { Menyusun regulasi terkait kewenangan } \\
\text { data (produsen Data) }\end{array}$ \\
\hline 4 & ACT-4 & $\begin{array}{l}\text { Penentuan klasifikasi data (Publik, } \\
\text { Rahasia) }\end{array}$ \\
\hline 5 & ACT-5 & $\begin{array}{l}\text { Membentuk Forum Data sebagai } \\
\text { platform komunikasi lintas OPD terkait } \\
\text { pengelolaan dan penyelenggaraan data } \\
\text { yang akuntabel dan berintegritas. }\end{array}$ \\
\hline 6 & ACT-6 & Menyusun arsitektur data dan aplikasi \\
\hline 7 & ACT-7 & $\begin{array}{l}\text { Membentuk Tim Integrasi Data dan } \\
\text { Aplikasi }\end{array}$ \\
\hline 8 & ACT-8 & Membentuk Tim Pengelola Data \\
\hline 9 & ACT-9 & Membentuk Tim Keamanan Informasi \\
\hline 10 & ACT-10 & Melakukan penetration testing \\
\hline 11 & ACT-11 & $\begin{array}{l}\text { Negosiasi dan review perjanjian } \\
\text { berbagi data (MoU) }\end{array}$ \\
\hline
\end{tabular}

\begin{tabular}{|c|c|c|}
\hline No & Kode & Aktivitas Tata Kelola Data \\
\hline 12 & ACT-12 & $\begin{array}{l}\text { Mengembangkan infrastruktur dan } \\
\text { sistem informasi untuk mengolah data }\end{array}$ \\
\hline 13 & ACT-13 & Melakukan analisis bisnis proses \\
\hline 14 & ACT-14 & $\begin{array}{l}\text { Menyusun standar pengembangan } \\
\text { infrastruktur dan sistem informasi }\end{array}$ \\
\hline 15 & ACT-15 & Melakukan scraping data \\
\hline 16 & ACT-16 & $\begin{array}{l}\text { Mengintegrasikan sistem informasi } \\
\text { dengan mengembangkan API }\end{array}$ \\
\hline 17 & ACT-17 & Mengembangkan sistem portal data \\
\hline 18 & ACT-18 & $\begin{array}{l}\text { Melakukan backup data secara berkala } \\
\text { dan melakukan restore data ketika } \\
\text { terjadi kehilangan dan kerusakan data }\end{array}$ \\
\hline
\end{tabular}

Setelah pemetaan peran tata kelola data dalam struktur organisasi pemerintahan Kabupaten Trenggalek, maka diperoleh peran aktivitas tata kelola data seperti yang diperlihatkan pada gambar 5 dengan menggunakan matrik RACI.

Dalam gambar tersebut, semua peran terkait tata kelola data dihubungkan untuk tiap masingmasing aktivitas tata kelola data disesuaikan dengan struktur organisasi pemerintah daerah Kabupaten Trenggalek.

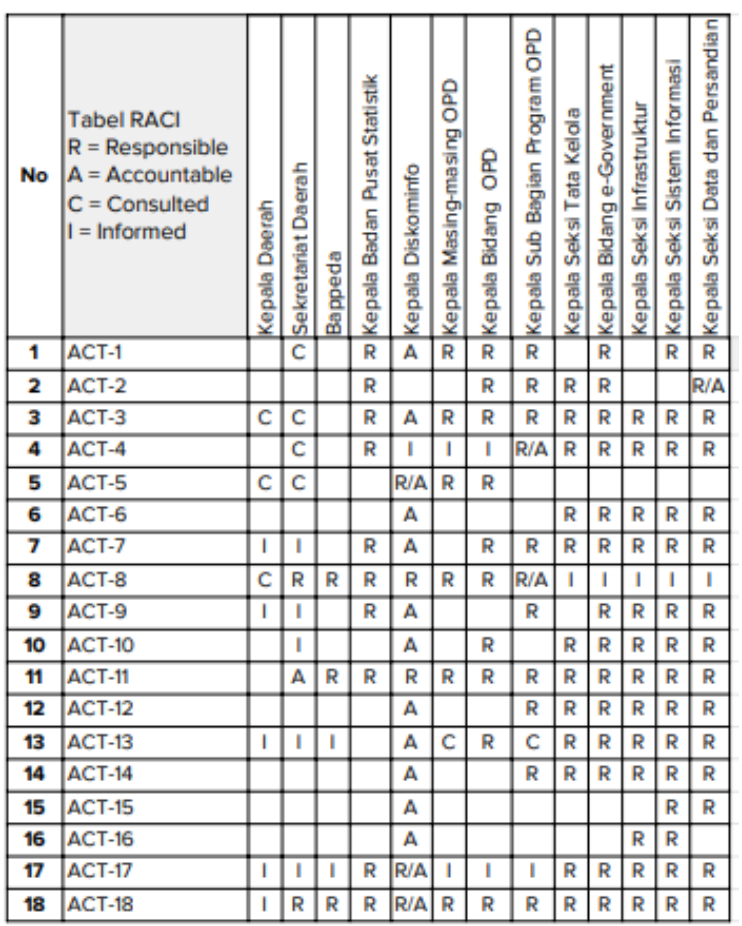

Gambar 5 Peran Aktivitas Tata Kelola Data 


\section{Pemetaan Masalah dengan Area Keputusan}

Berdasarkan identifikasi permasalahan data yang dimiliki oleh pemerintah Kabupaten Trenggalek, terdapat pemetaan dengan area keputusan saat ini dalam tata kelola data yang dilakukan untuk menemukan solusi permasalahan data. Pemetaan disiapkan dengan mencari hubungan antara setiap masalah dan hasil yang diperoleh dari kegiatan dalam tata kelola data yang ditentukan. Hasil pemetaan tersebut, dapat ditunjukkan pada gambar 6 .

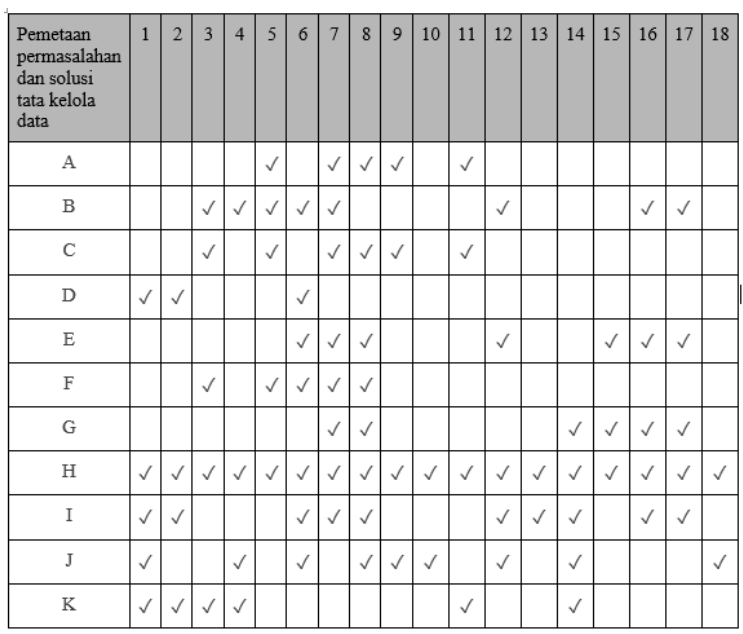

Gambar 6 Pemetaan Masalah Area Keputusan

\section{Konfirmasi Hasil Rancangan Struktur Tata Kelola Data}

Setelah merancang struktur tata kelola data Pemerintah Kabupaten Trenggalek yang terdiri dari peran, area keputusan, dan kewenangan, konfirmasi hasil rancangan dibuat agar dapat diimplementasikan sesuai dengan rencana dan kondisi yang ada.

Konfirmasi dilakukan langsung kepada pihak-pihak terkait dengan tata kelola data yang ada di Pemerintah Kabupaten Trenggalek dalam Forum Group Discussion dan wawancara dengan Dinas Pengelola TIK yaitu Dinas Komunikasi dan Infromatika Kabupaten Trenggalek .

\section{KESIMPULAN}

Peraturan Presiden no 39 tahun 2019 tentang Satu Data mengamanahkan untuk memperoleh data yang akurat, mutakhir, terpadu, dapat pertanggungjawabkan, mudah diakses, dan dibagipakaikan, diperlukan perbaikan tata kelola Data. Saat penelitian ini dilakukan Pemerintah Kabupaten Trenggalek belum mempunyai tata kelola data.

Penelitian ini berhasil merumuskan struktur tatakelola data di Pemerintah Kabupaten Trenggalek berdasarkan pedoman DMBOK. Hasil dari penelitian ini menunjukkan bahwa tata kelola data dengan pedoman DMBOK dapat digunakan sebagai solusi untuk masalah data yang terjadi.

Struktur tata kelola data yang telah dirancang diharapkan dapat membantu Kabupaten Trenggalek dalam mengimplementasikan tatakelola data di pemerintahan secara efektif

\section{DAFTAR PUSTAKA}

[1] DEPKOMINFO, "Kerangka Acuan dan Pedoman Interoperabilitas Sistem Informasi Instansi Pemerintah," no. January, p. 51, 2008.

[2] DAMA International, "DAMA International - DAMA-DMBOK (2nd Edition)_ Data Management Body of Knowledge-Technics Publications (2017)." p. 628, 2017.

[3] M. Aisyah and Y. Ruldeviyani, "Designing data governance structure based on data management body of knowledge (DMBOK) Framework: A case study on Indonesia deposit insurance corporation (IDIC)," 2018 Int. Conf. Adv. Comput. Sci. Inf. Syst. ICACSIS 2018, pp. 307-312, 2019, doi: 10.1109/ICACSIS.2018.8618151.

[4] Trenggalek, "Masterplan TI Kabupaten Trenggalek," Kabupaten Trenggalek, 2020.

https://renggalekkab.go.id/download/Pr esentasi-Masterplan-Trenggalek-DPRDBupati.pdf (accessed Jul. 07, 2020).

[5] N. Ruswianto, E. Utami, and M. R. Arief, "Perancangan Data Primer Untuk Layanan E-Government Berbasis Ketugasan Dengan Pendekatan Model Diagram Raci ( Study Kasus : Pemerintah Kota Magelang )," pp. 7-12, 2018.

[6] N. L. A. Laksmidewi, "Framework Interoperabilitas Data E-Government Provinsi Bali Dengan Cobit 4.1 Dan Iegif," Universitas Udayana, Bali, 2017.

[7] F. A. Tridalestari and H. N. Prasetyo, "Identifikasi Fungsi Tata Kelola Data Framework Dama International Pada Universitas X," vol. II, no. 1, pp. 45-54, 
2015.

[8] B. A. Nugraha, R. W. Witjaksono, and R. Mulyana, "ANALISIS DAN PERANCANGAN MASTER DATA MANAGEMENT ( MDM ) BERBASIS DAMA-DMBOK v2 ( Studi Kasus : PT . Kereta Api Indonesia )," e-Proceeding Art Des., vol. 5, no. 3, pp. 3282-3289, 2018.

[9] M. Z. Syafnel, I. Darmawan, and R. Mulyana, "Analisis Dan Perancangan Tata Kelola Data Sistem Pemerintahan Berbasis Elektronik Domain Master Data Management ( Mdm ) Pada Dama Dmbok V2 Di Diskominfotik Kbb Analysis and Design of Government Data Governance System Based on Electronic Domain Master Data," vol. 6, no. 2, pp. 7775-7786, 2019.

[10] S. B. Wibisono, A. N. Hidayanto, and W. S. Nugroho, "Data Quality Management Maturity Measurement of Government-Owned Property Transaction in BMKG," Commun. Inf. Technol. J., vol. 12, no. 2, 2018, doi: 10.21512/commit.v12i2.4470.

[11] Kemenkumham RI, "Kepres Satu Data," Kemenkumham RI, no. 004185, 2019.

[12] D. Kurniasih, A. Subagyo, and S. Agustina, "Penyusunan Tugas Dan Fungsi Perangkat Daerah Di Lingkungan Pemerintah Kabupaten Bandung," J. Ilmu Polit. dan Komun., vol. VI, no. 1, pp. 127-138, 2016.

[13] DAMA-DMBOK, The DAMA Guide to The Data Management Body of Knowledge (DAMA-DMBOK Guide). 1977.

[14] F. C. S. Adiyanta, "Hukum dan Studi Penelitian Empiris : Penggunaan Metode Survey sebagai Instrumen Penelitian Hukum Empiris," Adminitrative Law Gov. Journal., vol. 2, no. 4, pp. 697709, 2019.

[15] K. Trenggakek, "Organisasi Perangkat Daerah," Kabupaten Trenggalek, 2020. https://www.trenggalekkab.go.id/menu? page $=50 \&$ cat $=16$ (accessed Jul. 07, 2020).

[16] B. Trenggalek, "Peraturan Bupati Trenggalek no 34 Tahun 2016," 2016. 